\title{
Determinantes da Adoção da Tecnologia de Despolpamento na Cafeicultura ${ }^{1}$
}

Edson Zambon Monte*

Erly Cardoso Teixeira**

Resumo: Os cafeicultores de Venda Nova do Imigrante, ES, que em sua maioria são agricultores familiares, têm adotado novas tecnologias para melhorar a qualidade do café arábica produzido na região. O objetivo deste trabalho é identificar os fatores que determinam a adoção da tecnologia de despolpamento pelos cafeicultores do município. O modelo Logit é utilizado como instrumento metodológico. Observa-se, pelos resultados, que os aspectos relativos a associativismo, escolaridade, capital próprio, produtividade, rentabilidade e treinamento determinam a adoção da tecnologia de despolpamento. As variáveis que mais contribuem para a adoção da tecnologia de despolpamento são rentabilidade, associativismo e treinamento.

Palavras-chave: cafeicultura, adoção tecnológica, despolpamento.

Classificação JEL: C21, O3 e Q55

\footnotetext{
Abstract: The family farm coffee producers from Venda Nova do Imigrante, ES, have adopted the pulping technology to improve Arabic co-

${ }^{1}$ Os autores agradecem aos professores Fátima Marília Andrade de Carvalho, João Eustáquio de Lima e José Luís dos Santos Rufino, pelos valiosos comentários e sugestões a este trabalho.

* Economista; Banco de Desenvolvimento do Espírito Santo - BANDES.

edsonzambon@bandes.com.br

** Ph.D.; Professor Titular do Departamento de Economia Rural da Universidade Federal de Viçosa. teixeira@ufv.br
} 
ffee quality. The objective of this paper is to identify the adoption determinants of the pulping technology by the coffee producers. The Logit model is applied for data analysis. The pulping technology adoption is determined by the variables: coop affiliation, years of school, own capital stock, yield, profitability and training. The variables with greater marginal impact on coffee pulping technology adoption are: profitability, coop affiliation and training.

Key words: coffee plantation, technology adoption, pulping.

JEL Classification: C21, O3 \& Q55

\section{Introdução}

O aumento no preço dos fatores de produção e insumos agrícolas, aliado às oscilações constantes no preço do café, tem ocasionado, nos últimos anos, queda na renda e na competitividade da cafeicultura. Para superar este problema, os cafeicultores buscam novas tecnologias, com o objetivo de aumentar a produtividade e melhorar a qualidade do produto.

Desde o estudo pioneiro de Solow, o progresso tecnológico tem sido arrolado como determinante do desenvolvimento econômico, uma vez que os aumentos de produção observados não eram explicados pela proporcional utilização de fatores convencionais. Em meados da década de 1960, esse conceito passou a ser aplicado diretamente à agricultura, reconhecendo-se o importante papel da pesquisa para os incrementos na produção e produtividade, por meio da geração de novas técnicas produtivas em forma de conhecimentos diretamente aplicáveis à produção, e de conhecimentos incorporados em fatores utilizados no processo produtivo ${ }^{2}$.

Segundo BARROS e MANOEL (1988), no Brasil, a utilização dos insumos modernos na agropecuária se expandiu, principalmente, a partir do final dos anos 60, e mais intensamente a partir da década de 1970, devido ao incentivo à produção interna, sendo alguns deles proporcionados pelo II PND (Segundo Plano Nacional de Desenvolvimento, 1974/1979). Ainda de acordo com BARROS e MANOEL (1988), o pro-

${ }^{2}$ Esses aspectos são mais bem abordados por SILVA e CAMARGO (1986). 
cesso de modernização da agricultura brasileira somente se intensificou após a década de 1970 .

Neste contexto de modernização da agricultura, ALVES (1979) destaca o papel fundamental da educação e dos gastos públicos em pesquisa agronômica e extensão, no aumento da produtividade agrícola. O reconhecimento da contribuição da pesquisa agronômica para o crescimento da produção e da produtividade agrícola realçou sua relevância na geração de novas técnicas produtivas.

Um dos principais problemas da modernização está no custo e na transferência da tecnologia dos insumos considerados modernos. Normalmente, esses insumos são produzidos em países mais desenvolvidos, cuja transferência para outras regiões não tem o mesmo resultado, devido ao clima, solo, etc. Por isso, SCHULTZ (1965) enfatizou a importância do investimento no País, o qual seria utilizado na formação de centros de pesquisas, no setor industrial para a produção dos insumos pesquisados e na agricultura, mediante disponibilização de crédito, melhoria na educação, etc.

Para HAYAMI e HUTTAN (1988), a mudança técnica é obtida, ao longo de uma trajetória eficiente, por sinais de preço de mercado, desde que estes reflitam eficientemente mudanças na demanda e na oferta de produtos e fatores, e que haja interação efetiva entre os produtores rurais, instituições públicas de pesquisa e empresas agrícolas.

Diferentemente do modelo de Hayami e Ruttan, no modelo de investimento e mudança tecnológica endógena, CAVALLO e MUNDLAK (1982) manifestam que os movimentos nos preços dos fatores não são a única nem a mais importante causa da mudança tecnológica. A escolha da tecnologia pode ser limitada pela disponibilidade de capital dentro da economia ou setor. A acumulação de capital na economia favorece a adoção da técnica moderna. Além disso, os agentes econômicos, quando deparam com uma oportunidade de investimento, preocupam-se com a rentabilidade do investimento, ou seja, como e onde aplicar seus recursos de forma a maximizar o retorno do capital investido.

Neste particular, GARCIA e TEIXEIRA (1991) demonstraram que, no Brasil, o processo de mudança tecnológica é mais intensivo no subsetor agrícola exportador do que nos demais setores da economia, em virtude de sua maior acumulação de capital. 
De acordo com SHUMPETER (1985), quando o empresário utiliza o próprio capital, o lucro provocado pela venda desse bem é acrescentado ao capital, já convertido em meios de produção, promovendo a capitalização do empresário e estimulando-o a conceber novas combinações na busca do aumento do lucro. Assim, o risco de adoção de novas tecnologias diminui quando o empresário utiliza o próprio capital.

Uma vez que o avanço tecnológico é fundamental para que o produtor consiga um produto de melhor qualidade e tenha, conseqüentemente, boa lucratividade, alguns trabalhos têm sido desenvolvidos com o propósito de determinar quais fatores são responsáveis pela adoção de novas tecnologias. SILVA (2002), procurou identificar, juntamente com grandes produtores, quais fatores são determinantes da adoção na tecnologia "plantio direto" na cultura de soja em Goiás. Pelos resultados, verificou-se que as variáveis determinantes da mudança tecnológica são treinamento, rentabilidade, área, produtividade, investimento e capital próprio.

A cafeicultura somente ganhou mais destaque, em relação às tecnologias de produção e de pós-colheita, a partir da década de 1990, quando ocorreu a liberalização de mercado para a cultura. Isto promoveu o incentivo à melhoria da qualidade do café produzido e consumido internamente, assim como dos cafés exportados. Esse aumento de qualidade foi causado, também, pela vinda de multinacionais para o Brasil ao longo dos anos 90, fazendo com que os agentes do agronegócio aumentassem sua produtividade na cultura.

No Espírito Santo, visando à melhoria da qualidade do café produzido, foi lançado, em 1999, um projeto que deu grande impulso à produção de café nas montanhas do Estado: o Programa de Sustentabilidade para o Café das Montanhas do Espírito Santo. O projeto tem o objetivo de promover uma agricultura sustentável para a Região de Montanhas, na qual está inserido o município de Venda Nova do Imigrante, mapeando as áreas produtoras, traçando um perfil da qualidade do café nela produzido e promovendo a melhoria da qualidade do produto (VENDA NOVA, 2004).

Venda Nova do Imigrante produz em média 50 mil sacas de café por ano, com predominância do café arábica. A região tem, portanto, na cafeicultura, uma das principais fontes de renda. Além disso, ao 
considerar-se como propriedades familiares àquelas que possuem no máximo quatro módulos fiscais (PRONAF, 2005), e que em Venda Nova do Imigrante um módulo fiscal corresponde a 18 hectares, a maioria das propriedades do município, cerca de $90 \%$, pode ser considerada como de agricultura familiar.

Alguns cafeicultores do município, apoiados pela Cooperativa dos Cafeicultores das Montanhas do Espírito Santo (PRONOVA), têm adotado novas tecnologias, com o propósito de melhorar a qualidade do café arábica, sendo uma delas o despolpamento ${ }^{3}$. Logo, o objetivo deste trabalho é identificar os fatores que determinam a adoção da tecnologia de despolpamento pelos cafeicultores da região.

\section{Metodologia}

O tipo de amostra utilizado foi o aleatório simples. Para a seleção dos produtores representantes da amostra foi feito sorteio entre os elementos da população de cafeicultores existentes no município.

De acordo com FONSECA e MARTINS (1996), o cálculo para amostras de uma população finita apresenta-se na Expressão 1:

$$
n=\frac{Z^{2} \cdot p \cdot q \cdot N}{d^{2}(N-1)+Z^{2} \cdot p \cdot q}
$$

em que $n$ é tamanho da amostra; $Z$, abscissa da curva normal padrão; $p$, estimativa da verdadeira proporção de um dos níveis da variável escolhida, expresso em decimais; $q=1-p ; N$, tamanho da população; e $d$, erro amostral admitido, expresso em decimais.

Segundo a Secretaria Municipal de Agricultura de Venda Nova do Imigrante, o município possui aproximadamente 400 produtores de café. No entanto, não existe uma lista com todos os nomes dos produtores cadastrados, o que reduziu o número de cafeicultores para 323, os quais representaram a população de cafeicultores da região.

Ademais, utilizou-se para fins de cálculo mínimo de entrevistas um

${ }^{3} \mathrm{O}$ despolpamento consiste na retirada da casca dos frutos maduros ou cerejas utilizando-se um descascador mecânico, seguido da retirada ou não, da mucilagem (EMBRAPA, 2005). 
nível de probabilidade de $90 \%(Z=1,645)$, uma margem de erro de 10 $\%$ e um valor $(p)$ de $50 \%$, já que a proporção de produtores de café que adotam as tecnologias de pós-colheita é desconhecida. Conseqüentemente, o valor $(q)$ foi de $50 \%$.

Ao realizarem-se os cálculos foi encontrado um valor amostral $(n)$ de 56 , ou seja, da população total 56 produtores de café foram entrevistados. As entrevistas foram realizadas em janeiro de 2005.

Para verificar a influência das variáveis estudadas na probabilidade de adoção da tecnologia de despolpamento, foi especificado o modelo em que a variável dependente admite valores discretos, zero e um - variável binária. Um dos principais objetivos dos modelos de resposta binária é calcular a probabilidade de um indivíduo, com determinado conjunto de atributos, decidir sobre um dado evento.

A probabilidade de ocorrência de cada resposta binária é decorrente de um conjunto de atributos dos indivíduos, como nível educacional, renda, idade do agricultor, sexo etc. (GUJARATI, 2000). No modelo Logit é usada a função de distribuição acumulada logística, dada por:

$$
L\left(X_{i} \beta\right)=\frac{1}{1+e^{-X_{i} \beta}}
$$

em que $L$ representa a função de distribuição logística; $X_{i}$, vetor de variáveis independentes; $\beta$, vetor de parâmetros; e $e$, base do logaritmo natural.

Ao decidir sobre adotar ou não determinada tecnologia, o produtor certamente avaliará as vantagens e as desvantagens. Como os parâmetros desta decisão não são observáveis para cada propriedade $i$, podese definir uma variável latente ou não observada, $Y^{*}$, como

$$
Y_{i}^{*}=X_{i} \beta+\mu_{i}
$$

em que $Y_{i}^{*}$ é variável dependente, $i=1, \ldots, n ; \beta$, parâmetro; $X_{i}$, conjunto de variáveis explicativas, $i=1, \ldots, n$; e $\mu_{i}$, o erro aleatório.

A decisão de adoção pode ser descrita pela variável binária, $Y_{i}$, tal que $Y_{i}=1$, se o produtor adota tecnologia e $Y_{i}=0$, se não a adota. Esses valores observados de $Y_{i}$ estão relacionados $\operatorname{com} Y_{i}^{*}$, como segue: 


$$
\begin{aligned}
& Y_{i}=1 \text {, se } Y_{i}^{*}>0 \text {; e, } Y_{i}=0 \text {, se } Y_{i}^{*}=0 ; \\
& \operatorname{Prob}\left(Y_{i}=1\right)=\operatorname{Prob}\left(Y_{i}^{*}>0\right)=\operatorname{Prob}\left(\mu_{i}>-X_{i} \beta\right) \\
& \operatorname{Prob}\left(Y_{i}=0\right)=\operatorname{Prob}\left(Y^{*}=0\right)=\operatorname{Prob}\left(\mu_{i} \leq-X_{i} \beta\right) .
\end{aligned}
$$

O modelo é estimado pelo Método de Máxima Verossimilhança. A probabilidade de adoção da tecnologia de despolpamento (a) e a probabilidade de não-adoção da tecnologia (b) podem ser calculadas pelas seguintes expressões:

$$
\text { (a) } P_{i}=\frac{1}{1+e^{-X_{i} \beta}} \quad \text { e } \quad \text { (b) } 1-P_{i}=\frac{e^{-X_{i} \beta}}{1+e^{-X_{i} \beta}} \text {, }
$$

sendo $P_{i}$ igual à probabilidade de adoção da tecnologia de despolpamento; $1-P_{i}$, probabilidade de não-adoção da tecnologia de despolpamento; $X_{i}$, variáveis explicativas do modelo; e $\beta$, coeficiente das variáveis explicativas.

De forma a determinar os fatores que promovem a adoção de novos processos produtivos pelos produtores de café de Venda Nova do Imigrante, considerou-se como variável dependente, para este estudo, a adoção da tecnologia de despolpamento, com valor um se o produtor adota a tecnologia de despolpamento, e zero se não a adota.

As variáveis independentes são definidas a seguir.

\section{a) Área (AREA)}

Medida como a área total explorada com a cafeicultura, composta pela área explorada própria e pela arrendada, em hectares. $\mathrm{O}$ efeito marginal esperado é positivo, ou seja, um aumento na área explorada com café elevará a probabilidade de adoção da tecnologia de despolpamento.

b) Associativismo (AS)

Dado pela participação dos produtores de café de Venda Nova do Imigrante na cooperativa de produtores do município (PRONOVA). A variável é binária e admite valor um para os cafeicultores que são só- 
cios da cooperativa e zero para os que não o são. Espera-se um efeito marginal positivo, ou seja, quando o produtor participa da cooperativa ele tem maiores informações sobre a tecnologia de despolpamento, logo maior a probabilidade de adoção de tal tecnologia.

c) Capital próprio (KP)

Medido pela proporção de capital próprio convertido pelo produtor em investimentos na propriedade, seja em benfeitorias, máquinas ou equipamentos, em relação ao volume total de gastos realizados (capital próprio para custeio da safra agrícola e investimento, mais crédito de custeio, mais crédito de investimento), em média, nas últimas cinco safras agrícolas. $\mathrm{O}$ resultado esperado do efeito marginal é positivo, ou seja, quanto mais capitalizado estiver o produtor, menor será sua aversão ao risco, sendo maior a probabilidade de adoção da tecnologia de despolpamento.

d) Crédito de custeio e de investimento (CRED)

Representado pelo valor médio de crédito de custeio e crédito de investimento, gasto pelo produtor para custear a safra agrícola e adquirir máquinas e equipamentos, nas últimas cinco safras. Acredita-se que, quanto maior a utilização do crédito de custeio e de investimento pelo produtor, maior a possibilidade de adoção das tecnologias de pós-colheita.

e) Escolaridade (ES)

Medida pelo total de anos que o produtor freqüentou a escola. Espera-se que quanto maior o nível de escolaridade, maior a facilidade de compreensão e assimilação da nova tecnologia e, conseqüentemente, maior a probabilidade de adoção da tecnologia de despolpamento.

f) Produtividade (PROD)

Determinada pela produtividade média alcançada nas últimas cinco safras, em sacas por hectare, para corrigir a sazonalidade do ciclo produtivo. O resultado esperado do efeito marginal é positivo, dado que a 
maior produtividade significa uso mais eficiente dos fatores e menor custo unitário, favorecendo a adoção das tecnologias de pós-colheita.

\section{g) Rentabilidade (R)}

Representada pelo preço recebido pelo produtor. Optou-se pelo uso da variável binária da seguinte forma: no momento da comercialização da última safra, se o produtor considerar baixo o preço recebido, a variável admitirá valor igual a zero; se considerá-lo médio/alto (médio ou alto), a variável admitirá valor igual a um. Espera-se que quanto maior a rentabilidade ou o preço recebido, maior a probabilidade de adoção da tecnologia de despolpamento.

h) Treinamento $(\mathrm{T})^{4}$

Representado pela participação do produtor, do administrador e dos funcionários em cursos de natureza técnica, com vistas em sua capacitação no manuseio de máquinas e equipamentos e no desenvolvimento correto das técnicas de pós-colheita, como forma de melhorar a qualidade do café produzido, e/ou pelo recebimento de assistência técnica durante a safra. A variável admite valor um para quem já recebeu algum tipo de treinamento e zero para quem não recebeu. O resultado esperado no efeito marginal é positivo, ou seja, com efetivação de treinamento, aumenta a probabilidade de adoção da tecnologia de despolpamento.

Para determinar o efeito marginal de cada variável sobre a probabilidade de adoção de uma dada tecnologia, é necessário usar os valores médios das variáveis explicativas.

O efeito marginal da variável $X_{i}$ sobre a variável dependente é descrito pela expressão:

$$
\begin{aligned}
& \frac{\partial P_{i}}{\partial X_{i}}=\beta \times \frac{1}{1+e^{-X_{i} \beta}} \times \frac{e^{-X_{i} \beta}}{1+e^{X_{i} \beta}}, \\
& \text { considerando-se } P_{i}=\frac{1}{1+e^{-X_{i} \beta}} \text { e } 1-P_{i}=\frac{e^{-X_{i} \beta}}{1+e^{-X_{i} \beta}} .
\end{aligned}
$$

\footnotetext{
${ }^{4}$ Assistência técnica foi considerada como treinamento.
} 
Observa-se que o efeito marginal da cada variável explicativa sobre a probabilidade não é constante, visto que depende do valor médio de cada variável $X_{i}$.

\section{Resultados e discussões}

Nesta seção, inicialmente é feita uma caracterização dos cafeicultores que adotam a tecnologia de despolpamento e daqueles que não a adotam. Posteriormente, são apresentados os resultados estimados pelo modelo Logit, seguido da interpretação das variáveis determinantes da adoção da tecnologia de despolpamento.

\subsection{Características dos produtores e determinantes da adoção de despolpa de café}

\subsubsection{Caracterização dos cafeicultores}

Em Venda Nova do Imigrante, 42,86\% dos cafeicultores despolpam o café, e $57,14 \%$ não o fazem. A área média das propriedades é de 22,71 hectares, com amplitude de três a 125 hectares. No que se refere à área explorada com café, a média é de 16,52 hectares, com amplitude de dois a 110 hectares.

Quanto à adoção de novas tecnologias, 70\% dos cafeicultores aguardam os resultados dos vizinhos ou dos produtores inovadores para depois aderirem ou não às inovações que o mercado oferece. Cerca de $20 \%$ utilizam as novas tecnologias de acordo com o orçamento e planejamento, e apenas $10 \%$ utilizam-nas à primeira vista.

Na Figura 1 é apresentado o grau de escolaridade dos cafeicultores. Nota-se que os produtores que despolpam café possuem maior grau de instrução do que aqueles que não o fazem. Para a faixa com nível educacional superior, o percentual de cafeicultores que adotam novas tecnologias é o dobro dos que não adotam-nas. Já para a faixa com $1^{\circ}$ grau completo, ocorre predominância de produtores de café que não despolpam. 
Figura 1 - Grau de escolaridade dos cafeicultores, em percentuais, de acordo com a adoção ou não da tecnologia de despolpamento, em Venda Nova do Imigrante, ES, 2005.

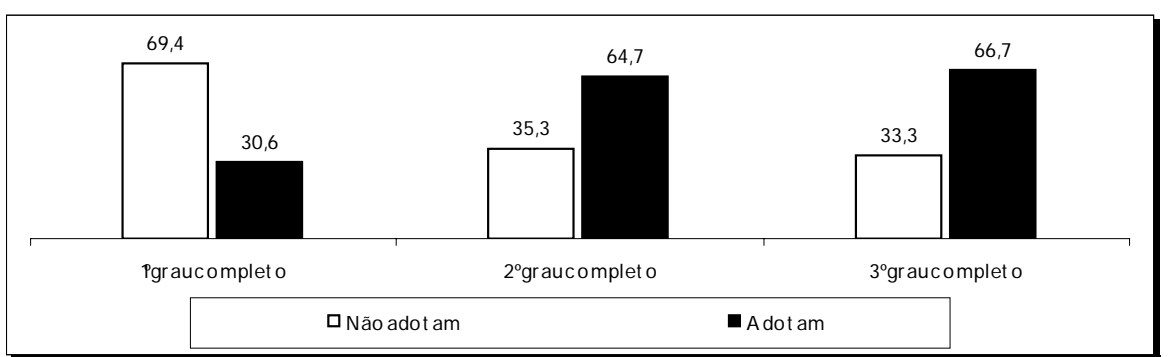

Fonte: Elaborado a partir dos questionários aplicados na pesquisa.

Na Tabela 1 são apresentados os valores médios das variáveis determinantes da tecnologia de despolpamento. Os cafeicultores que adotam tal tecnologia têm para as variáveis contínuas, valores médios maiores do que aqueles que não a adotam. $\mathrm{O}$ teste de diferenças de médias foi estatisticamente não-significativo, a 5\% de significância, para AREA e CRED, ou seja, as médias de cada uma dessas duas variáveis podem ser consideradas iguais, o que implica que os dois grupos de cafeicultores vêm da mesma população. Portanto, essas variáveis não afetam a probabilidade de adoção. Para as variáveis AS, ES, KP e PROD, o teste foi estatisticamente significativo a $5 \%$ de probabilidade.

Tabela 1 - Valores médios das variáveis contínuas determinantes da adoção da tecnologia de despolpamento, em Venda Nova do Imigrante, ES, 2005

\begin{tabular}{cccc}
\hline Variáveis & $\begin{array}{c}\text { Média geral } \\
(1)\end{array}$ & $\begin{array}{c}\text { Média para os que não } \\
\text { adotam }(2)\end{array}$ & $\begin{array}{c}\text { Média para os que } \\
\text { adotam (3) }\end{array}$ \\
\hline AREA & 16,52 & $12,16^{\mathrm{b}}$ & $22,34^{\mathrm{b}}$ \\
CRED & $2.915,71$ & $1.599,38^{\mathrm{b}}$ & $4.670,83^{\mathrm{b}}$ \\
ES & 7,77 & $6,31^{\mathrm{a}}$ & $9,71^{\mathrm{a}}$ \\
PROD & 26,10 & $21,97^{\mathrm{a}}$ & $31,61^{\mathrm{a}}$ \\
KP & 0,50 & $0,36^{\mathrm{a}}$ & $0,69^{\mathrm{a}}$ \\
\hline
\end{tabular}

Fonte: Elaborado a partir dos questionários aplicados na pesquisa.

Nota: 1) Nível de significância estatística das médias: 5\% (a = estatisticamente significativo, b = não-significativo);2) AREA = área explorada com a cultura de café; $\mathrm{CRED}$ = valor médio de crédito de custeio e de investimento, utilizado na safra agrícola; $\mathrm{ES}=$ escolaridade do produtor; $\mathrm{KP}$ = capital próprio convertido em investimentos na propriedade; e PROD = produtividade (sc/ha). 
Dentre as variáveis contínuas, destaca-se o capital próprio (KP). Esta apresentou média geral de 0,50, o que indica a proporção de recursos próprios convertidos em investimentos na propriedade, seja em benfeitorias, máquinas ou equipamentos, em relação ao volume total de gastos (capital próprio para custeio da safra agrícola, mais crédito de custeio, mais crédito de investimento), ou seja, para cada real aplicado na cultura de café, em média $\mathrm{R} \$ 0,50$ (cinqüenta centavos) são de capital próprio, isto é, a metade dos recursos é própria e aplicada em investimentos. Para os cafeicultores que não utilizam a tecnologia de despolpamento, a média foi de $\mathrm{R} \$ 0,36$ (trinta e seis centavos) e, para aqueles que a utilizam, foi de $\mathrm{R} \$ 0,69$ (sessenta e nove centavos).

\subsubsection{Fatores que determinam à adoção da tecnologia de despolpamento}

Na Tabela 2 são apresentados os coeficientes estimados por meio do modelo Logit, para os fatores que determinam à adoção da tecnologia de despolpamento com as respectivas significâncias estatísticas.

O índice de razão de verossimilhança encontrado após o ajustamento da equação, que representa a probabilidade de adoção da tecnologia de despolpamento, foi de 0,72 , ou seja, $72 \%$ das variações que ocorrem na probabilidade de adoção são explicadas pelas variações das variáveis independentes do modelo.

No modelo ajustado foram identificadas seis variáveis estatisticamente significativas, a saber: associativismo (AS), escolaridade do produtor (ES), capital próprio (KP), produtividade (PROD), rentabilidade (R) e treinamento (T). Assim, os coeficientes dessas variáveis são estatisticamente diferentes de zero, influenciando na probabilidade de adoção da tecnologia de despolpamento. As variáveis área explorada com a cultura cafeeira (AREA) e crédito de custeio e investimento (CRED) não foram estatisticamente significativas, ou seja, não determinam a adoção da tecnologia de despolpamento. 
Tabela 2 - Coeficientes estimados do modelo Logit para os determinantes da adoção da tecnologia de despolpamento, em Venda Nova do Imigrante, ES, 2005

\begin{tabular}{ccccc}
\hline Variáveis & Coeficientes & Erro-padrão & Valor de Z & Prob. \\
\hline C & -15.91619 & 5.505180 & -2.891130 & 0.0038 \\
AREA & 0.046745 & 0.063888 & 0.731675 & $0.4644^{\text {ns }}$ \\
AS & 4.583077 & 1.682881 & 2.723352 & $0.0065^{* * *}$ \\
CRED & 0.000212 & 0.000258 & 0.823182 & $0.4104^{\text {ns }}$ \\
ES & 0.395473 & 0.217250 & 1.820359 & $0.0687^{*}$ \\
KP & 2.650619 & 1.335340 & 1.984977 & $0.0471^{* *}$ \\
PROD & 0.199707 & 0.100428 & 1.988553 & $0.0468^{* *}$ \\
R & 5.474656 & 1.822255 & 3.004331 & $0.0027^{* *}$ \\
T & 2.898947 & 1.481860 & 1.956290 & $0.0504^{*}$
\end{tabular}

Obs. com variável dependente $=\begin{array}{ll}0 & 32\end{array}$

Obs. com variável dependente $=124$

Índice de razão de verossimilhança 0,72

Total obs.: 56

Probabilidade (LR estat.) 1.51E-09

Fonte: Elaborado a partir dos dados da pesquisa.

1) *** Significativo a $1 \%,{ }^{* *}$ Significativo a $5 \%$, * Significativo a $10 \%$, ns Não-significativo a $10 \%$;

2) $\mathrm{C}=$ constante; AREA = área explorada com a cultura de café; $\mathrm{AS}=$ associativismo; CRED = valor médio de crédito de custeio e de investimento, utilizado na safra agrícola; ES = escolaridade do produtor; $\mathrm{KP}=$ capital próprio convertido em investimentos na propriedade; $\mathrm{PROD}=$ produtividade $(\mathrm{sc} / \mathrm{ha}) ; \mathrm{R}=$ rentabilidade (preço recebido pela saca de café, considerado baixo ou médio/alto); e $\mathrm{T}=$ treinamento (participação em cursos de natureza técnica e presença de assistência técnica).

A variável associativismo (AS) possui grande efeito sobre a adoção da técnica de despolpamento, uma vez que a maior parte do café despolpado do município é comercializada via (PRONOVA), e esta oferece vários cursos e treinamentos voltados para o manuseio de novas tecnologias na cultura cafeeira.

O coeficiente da variável escolaridade (ES) foi estatisticamente significativo. Maior nível de escolaridade facilita a compreensão e assimilação de novas tecnologias e, conseqüentemente, eleva a probabilidade de adoção de novas tecnologias.

O capital próprio (KP) influencia na adoção da tecnologia de despolpamento. Quando o empresário utiliza seu próprio capital, o lucro provocado pela venda desse bem é acrescentado ao capital, já convertido em meios de produção, promovendo a capitalização do empresário e estimulando-o a conceber novas combinações na busca do aumento 
do lucro. Portanto, quanto mais capitalizado estiver o produtor, menor o risco de adoção de novas tecnologias (SHUMPETER, 1985).

A rentabilidade (R) é a variável mais importante na adoção da tecnologia de despolpamento. Quanto maior a diferença entre as taxas de retorno da nova e da velha técnica, mais rápida a mudança nas técnicas, ou seja, níveis mais avançados de tecnologia serão desejados à medida que estejam associados à expectativa de retornos mais elevados (CAVALLO e MUNDLAK, 1982).

No que se refere à variável produtividade (PROD), esta apresentou-se estatisticamente significativa. Os produtores que despolpam aplicam melhores técnicas de lavagem, secagem, beneficiamento, que são responsáveis pela maior produtividade de café de melhor qualidade. O treinamento ( $\mathrm{T}$ ) tem impacto positivo, dado que novas tecnologias necessitam de maiores conhecimentos para serem trabalhadas de forma adequada.

Os coeficientes das variáveis explicativas, estimados pelo modelo Logit, não refletem o efeito marginal dessas sobre a probabilidade de adoção da tecnologia de despolpamento. Para determinação do efeito marginal de cada variável sobre a probabilidade de adoção, são usados os valores médios das variáveis explicativas, apresentados na Tabela 1, coluna 1, de acordo com a expressão 7 .

Na Tabela 3 são apresentados os valores dos efeitos marginais das variáveis associativismo (AS), escolaridade (ES), capital próprio (KP), produtividade (PROD), rentabilidade $(R)$ e treinamento $(T)$, sobre a adoção da tecnologia de despolpamento. A variável AS teve efeito marginal igual a 0,4834, o que significa que a participação do cafeicultor na cooperativa de produtores provoca aumento na probabilidade de adoção da tecnologia de despolpamento de 48,34 pontos percentuais.

A ES teve efeito marginal igual a 0,0417, o que implica que, para cada ano a mais de escolaridade, a probabilidade de o produtor despolpar café eleva-se em 4,17 pontos percentuais. Maior conhecimento é necessário para lidar com as novas tecnologias; logo, maior nível de escolaridade é fundamental para o produtor investir de forma correta.

A variável KP obteve efeito marginal de 0,2796, ou seja, à medida em que aumenta a proporção de capital próprio convertido em investimentos na propriedade, em relação ao total de gastos, a probabilidade 
de adoção se eleva em 27,96 pontos percentuais. O efeito marginal da variável PROD foi de 0,0211, logo, para cada saca a mais por hectare, há elevação na probabilidade de adoção de 2,11 pontos percentuais.

Tabela 3 - Efeitos marginais das variáveis determinantes da adoção da tecnologia de despolpamento, pelo modelo Logit, em Venda Nova do Imigrante, ES, 2005

\begin{tabular}{cc}
\hline Variáveis & Efeito marginal \\
\hline AS & 0,4834 \\
ES & 0,0417 \\
KP & 0,2796 \\
PROD & 0,0211 \\
R & 0,5774 \\
T & 0,3058 \\
\hline
\end{tabular}

Fonte: Elaborado a partir dos dados da pesquisa.

Nota: 1) AS = variável binária associativismo; $\mathrm{ES}=$ escolaridade do produtor; $\mathrm{KP}$ = capital próprio convertido em investimentos na propriedade; $\mathrm{PROD}=$ produtividade (sc./ha); $\mathrm{R}=$ variável binária rentabilidade (preço recebido pela saca de café, considerado alto, médio ou baixo); $\mathrm{T}=$ variável binária treinamento.

O efeito marginal da variável (R), considerada a mais importante, é igual a 0,5774 , o que implica que, na presença de rentabilidade média/ alta, a probabilidade de adoção eleva-se em 57,74 pontos percentuais. Com maior lucratividade, o cafeicultor se sente mais propenso a investir, uma vez que, ao final da safra, os custos da produção poderão ser compensados com o lucro advindo da cultura.

Para a variável T o efeito marginal foi de 0,3058 , ou seja, com treinamento, a probabilidade de adoção da tecnologia de despolpamento aumenta em 30,58 pontos percentuais. Como a técnica de despolpamento é recente na região, os cursos e treinamentos referentes a tal tecnologia são fundamentais para que os cafeicultores a manuseiem de forma correta, o que torna o efeito marginal da variável T expressivo.

\section{Conclusões}

Em Venda Nova do Imigrante, devido às condições climáticas, o emprego de novas tecnologias é fundamental para que o cafeicultor consiga maior rentabilidade e competitividade na cultura. Neste contexto, a 
tecnologia de despolpamento apresenta-se como a mais importante no processo de pós-colheita do café, pois gera melhor qualidade do produto, e conseqüentemente, maior lucratividade e competitividade.

As variáveis rentabilidade (R), associativismo (AS), capital próprio (KP) e treinamento (T) são as mais importantes quanto à adoção da tecnologia de despolpamento, respectivamente.

O despolpamento do café eleva os custos de produção, tanto na colheita como na pós-colheita. Portanto, para sua utilização, é necessário um preço mais elevado pelo produto, que cubra tais custos e gere maior lucratividade para o cafeicultor. Além disso, é uma tecnologia, que para ser trabalhada de forma adequada, requer capacitação, que provém de cursos e treinamentos.

Os resultados deste trabalho assemelham-se aos encontrados por SILVA e TEIXEIRA (2002), para grandes produtores de soja, no Estado de Goiás. Assim, a adoção de novas tecnologias, tanto para grandes produtores quanto para agricultores familiares, parece ser determinada pelos mesmos fatores, principalmente rentabilidade (R), associativismo (AS), treinamento ( $\mathrm{T}$ ) e capital próprio (KP).

Portanto, políticas governamentais que incentivem os produtores rurais, neste caso particular os cafeicultores, a buscarem novas tecnologias, são necessárias para melhoria da qualidade do café e aumento da competitividade da cultura cafeeira. Dentre estas políticas, destacam-se os gastos públicos em pesquisa agronômica e extensão, dado que aumentam a produtividade agrícola (ALVES, 1979). Também são importantes os investimentos internos na formação de centros de pesquisa, e na agricultura, mediante disponibilização de crédito, melhoria na educação, etc. (SCHULTZ, 1965).

\section{Referências bibliográficas}

ALVES, E. R. A. A produtividade da agricultura. Brasília: EMBRAPA. 1979, 56 p.

BARROS, J. R. M.; MANOEL A. Insumos agrícolas: evolução recente e perspectivas. In: BRANDÃO, A. S. P. Os principais problemas da agricultura brasileira: análise e sugestões, Rio de Janeiro, IPEA/INPES, 1988, p. 295-332. 
CAVALLO, D., MUNDLAK, Y. Agriculture and economic growth in an open economy: the case of Argentina. Washington, D. C.: International Food Policy Research Institute. 1982, 162 p. (Research Report, n. 36).

EMPRESA BRASILEIRA DE PESQUISA AGROPECUÁRIA - EMBRAPA. Serviços - Sistema de Produção - Café. Disponível em: < http://www. cnpab.embrapa.br > . Acesso em: 08 de agosto de 2005.

FONSECA, J. S.; MARTINS, G. A. Curso de estatística. São Paulo: $6^{\mathrm{a}}$ ed. São Paulo: Atlas, 1996. 320 p.

GARCIA, S.; TEIXEIRA, E. Investimento e mudança tecnológica na economia brasileira. Revista brasileira de economia, v. 45, n. 4, p. 565591, 1991.

GUJARATI, D. N. Econometria básica. São Paulo: MAKRON Books, 2000, 845 p.

HAYAMI, Y., RUTTAN, V. Desenvolvimento agrícola: teoria e experiências internacionais. Brasília: EMBRAPA, 1988. 367 p.

PROGRAMA NACIONAL DE FORTALECIMENTO DA AGRICULTURA FAMILIAR - PRONAF. Quem somos? - Perguntas. Disponível em: < http://www.pronaf.gov.br > . Acesso em: 21 de agosto de 2005.

SCHULTZ, T. W. A transformação da agricultura tradicional. Rio de Janeiro: Zahar, 1965. 207 p.

SCHUMPETER, J. A. A teoria de desenvolvimento econômico. São Paulo: Nova Cultura, 1985. 169 p.

SILVA, G. L. S. P.; CAMARGO, H. C. E. Como medir a produtividade agrícola: conceitos, métodos e aplicações. IEA/SP. Relatório de pesquisa, n. 3, 29 p. 1986.

SILVA, S. P. ; TEIXEIRA, E. C. Determinantes da adoção da tecnologia "plantio direto" na cultura da soja em Goiás. Revista de Economia e Sociologia Rural. v. 40, n. 2, p. 305-326, 2002.

VENDA NOVA (2004). Histórico - História da cidade. Disponível em: < http://www.vendanova.com.br > . Acesso em: 11 de fevereiro de 2004.

Recebido em novembro de 2005 e revisto em abril de 2006 